\title{
Reply to response to "What Do Aquaporin Knockout Studies Tell Us about Fluid Transport in Epithelia?" Maclaren OJ, Sneyd J, Crampin EJ (2013) J Membr Biol 246:297305
}

\author{
Oliver J. Maclaren ${ }^{1 *} \quad$ James Sneyd ${ }^{2}$ \\ Edmund J. Crampin ${ }^{3}$ \\ ${ }^{1}$ Mathematical Institute, University of Oxford. \\ ${ }^{2}$ Department of Mathematics, The University of Auckland. \\ ${ }^{3}$ Melbourne School of Engineering, The University of Melbourne
}

December 31, 2013

*Corresponding author (OJM)

Email: maclaren@maths.ox.ac.uk

Mathematical Institute, University of Oxford

Andrew Wiles Building, Radcliffe Observatory Quarter, Woodstock Road, Oxford, OX2 6GG

Phone: +4401865 615166 


\section{Reply to A.E. Hill and Y. Shachar-Hill}

Dear Sir,

In their response (Hill and Shachar-Hill, 2013) to our article "What do aquaporin knockout studies tell us about fluid transport in epithelia?" (Maclaren et al., 2013), in which they also comment on another previous article of ours (Maclaren et al., 2012), A.E. Hill and Y. Shachar-Hill make a number of incorrect and misleading statements about the content of our articles.

Firstly, the correspondents claim that we incorrectly use the osmotic theory - in particular that at some point our development of the osmotic theory is "unaccountably abandoned" (p. 665). They then proceed to follow the same process as in our article to arrive at exactly the same equation - compare their equation (2) (p. 665) with our equation (11) (Maclaren et al., 2013, p. 300). Further, they claim that we "make no reference whatsoever to the epithelial systems studied in which AQP KOs had no effect" (p. 666). This again is a severe misrepresentation - one of the three systems discussed in our article is very specifically a system of this type - the lung alveolus (type I cells). The correspondents needed only consult Figure 2, Tables 1 and 2, not to mention the text of actual article itself to notice this.

The correspondents go on to state that "these [cases in which AQP KOs have no effect] cannot simply be dismissed as examples of extreme nonlinearity" (p. 666). Firstly, we should emphasise that any discussion of linearity or nonlinearity should state what quantity is linear/nonlinear in what other quantity; with that aside, in this case, we have precisely the opposite of 'explaining away with nonlinearity'. In these regimes, the water permeability is sufficiently large that changes in water transport are expected to be linear in, i.e. directly proportional to, changes in solute transport, while the water transport is essentially independent of, i.e. constant with respect to variations in, the water permeability. Another way of saying this is that the water flux is tightly coupled to the solute flux and is insensitive to changes in water permeability for regimes in which the water permeability is sufficiently large relative to solute transport. It is in the cases in which knockout effects are significant, which occur when the water permeability is sufficiently reduced relative to solute transport, that one would expect nonlinear relationships. In this case, water flux decreases in a non-proportional manner with reductions in water permeability and solute transport. Both of these parameter regimes in our mathematical model correspond to what is observed experimentally, and easily explain what A. E. Hill and $\mathrm{Y}$. Shachar-Hill apparently want to turn into a paradox.

Yours sincerely,

Oliver J. Maclaren, James Sneyd and Edmund J. Crampin

\section{References}

Hill, A. E. and Shachar-Hill, Y. (2013). Response to "What do aquaporin knockout studies tell us about fluid transport in epithelia?" Maclaren OJ, Sneyd J, Crampin EJ (2013) J Membr Biol 246: 297-305. The Journal of Membrane Biology, 246(9):665-667.

Maclaren, O. J., Sneyd, J., and Crampin, E. J. (2012). Efficiency of primary saliva secretion: An analysis of parameter dependence in dynamic single-cell and ac- 
inus models, with application to aquaporin knockout studies. The Journal of Membrane Biology, 245:29-50.

Maclaren, O. J., Sneyd, J., and Crampin, E. J. (2013). What do aquaporin knockout studies tell us about fluid transport in epithelia? The Journal of Membrane Biology, 246:297-305. 


\section{University Library}

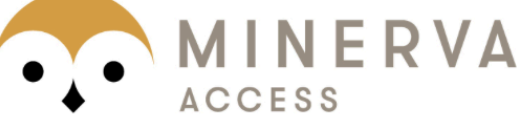

A gateway to Melbourne's research publications

Minerva Access is the Institutional Repository of The University of Melbourne

Author/s:

Maclaren, OJ;Sneyd, J;Crampin, EJ

Title:

Reply to Response to 'What Do Aquaporin Knockout Studies Tell Us about Fluid Transport in Epithelia?' Maclaren OJ, Sneyd J, Crampin EJ (2013) J Membr Biol 246:297-305

Date:

2014-03-01

Citation:

Maclaren, O. J., Sneyd, J. \& Crampin, E. J. (2014). Reply to Response to 'What Do Aquaporin Knockout Studies Tell Us about Fluid Transport in Epithelia?' Maclaren OJ, Sneyd J, Crampin EJ (2013) J Membr Biol 246:297-305. JOURNAL OF MEMBRANE BIOLOGY, 247 (3), pp.289-290. https://doi.org/10.1007/s00232-013-9628-6.

Persistent Link:

http://hdl.handle.net/11343/282756 